place for research, and despite the ingenious makeshifts its deficiencies have called forth, has now become almost intolerable. It is proposed to adapt this laboratory for the Department of Geology, at present cramped in the Museum itself, and to erect and equip a new building near the old and consequently near the other Physics Department, the Electrical Laboratory. The Clarendon should be a suitable place for the Department of Geology, which under the new professor to be elected soon should readily take on a new lease of life within it. Next, it is intended to build a physical-chemistry institutethe first University building for this subject-not, as might be thought most convenient, next to the Inorganic Laboratory (there is quite insufficient space available there for an adequate new building, es: pecially when possible extensions of both departments are envisaged), but immediately on the other side of the Organic Chemistry Laboratory from it. Researchers in physical chemistry who now do their work in the laboratories and cellars of Balliol, Trinity and Jesus Colleges, overflowing at times into the engineering and organic chemistry laboratories, should find in the intended University institute an ampler and much more convenient home. After that building has gone up, it is hoped to rebuild, near by, the Physiology Laboratory, which dates from 1884.

\section{Reflection of Radio Waves from the Middle Atmosphere}

THE method of studying the ionized regions of the upper atmosphere by emitting small pulses of electric waves and recording the echoes reflected from the ionosphere is now well-known and is in everyday use in many parts of the world. The commonly recognized reflecting regions are at heights of $80 \mathrm{~km}$. and above. Communications to the correspondence columns of NATURE of May 9 and 23, 1936, described observations indicating the existence of reffecting regions at much lower heights. These new regions were first discovered in May 1935, and an account of their investigation over a period of about a year from that date was given in a paper presented on February 4 to the Royal Society by R. A. Watson Watt, A. F. Wilkins and E. G. Bowen. A summary of the paper will be found on page 299. It appears from this work that there may be three electrified regions in the middle atmosphere at average heights of 10,40 and $60 \mathrm{~km}$., which are capable of reflecting radio waves of frequencies of the order of 6 megacycles per second and above (wave-lengths 50 metres and below). The lowest region has been found to be stratified to such an extent as to indicate the existence of five distinct layers at heights between 8.5 and $13.5 \mathrm{~km}$., with reflection coefficients as high as $0 \cdot 7$. The observations so far made do not indicate any marked diurnal or seasonal changes. An interesting feature of the investigation so far conducted is that echoes from these layers have been recorded at sensibly vertical incidence at wavelengths at and below those now in use for the television service. The existence of such echoes would cause the picture seen in a television receiver to have a doubled or blurred appearance. There is, however, insufficient evidence available to state how serious this possibility may be in the development of television services on the wave-lengths at present in use.

\section{Auroral Display on February 3}

REPORTS from various observers in Yorkshire and south Lancashire, who witnessed a display of the aurora borealis in the evening of February 3 last, have appeared in the Yorkshire Post. The aurora, which was evidently a striking phenomenon to those favoured with a clear sky, began about $18^{\mathrm{h}} 30^{\mathrm{m}}$ and lasted for an hour. One observer at Bradford noted a broad band of red passing overhead from east to west. On inquiry at the Royal Observatory, Greenwich, it was stated that a magnetic disturbance, which could be associated with this aurora, had been recorded at the Abinger magnetic station. The disturbance began suddenly on February 2 at $23^{\mathrm{h}} 5^{\mathrm{m}}$ U.T., and within a few hours a range of $220 \gamma$ in horizontal force had been registered. The disturbance then died down, but was renewed between $17^{\mathrm{h}}$ and $22^{\mathrm{h}}$ on February 3 ; a typical movement (associated with auroras) in declination occurred about $19^{\mathrm{h}}$ with a rang $\partial$ of $\frac{3}{4}^{\circ}$, the range in horizontal force being $190 \gamma$. At the commencement of the magnetic disturbance on Feb. $2^{\mathrm{d}} 23^{\mathrm{h}}$, the centre of the large sunspot, reported on p. 228 of NATURE of February 6, was about $40^{\circ}$ west of the sun's central meridian and the following extremity of the spot about $32^{\circ}$ west. A statistical analysis made at Greenwich of big sunspots and associated magnetic storms shows that spots of the size of the recent one are associated, in about two out of three cases, with either a large or a small magnetic storm, occurring on the average about $1 \frac{1}{2}$ days after the central meridian passage of the spot. It may be added that 27 days (or a solar synodic rotation) before the aurora on February 3, the Abinger magnetic traces at about $19 \frac{1}{2}^{\mathrm{h}}$ on January 7 show a movement distinctive of auroral activity. An observer at the Saltburn Coastguard Station who saw the aurora on February 3 is reported by the Yorkshire Post as having stated that he "saw the lights a month ago".

\section{The United States Floods}

WHILST it is fully expected that the liability of the countryside to flooding through the possible bursting of the riverside levees in the Mississippi Valley will continue to be a menace for another week or ten days, yet there has been a perceptible diminution in the anxiety felt as regards the general situation, which is much more satisfactory than at the time of our previous issue. The crest of the flood wave is gradually diminishing in height. It did not quite reach the anticipated level at Cairo, and as it passes down the valley, unless reinforced by fresh rains, it should subside in intensity. There is believed to be a margin of at least four feet available above water surface level from New Madrid to New Orleans, and this should be adequate for the occasion. None the less, caution is being exercised, and some 120,000 workmen are being kept on the alert along the course 